\title{
Admission Cardiotocography in High Risk Pregnancies
}

\section{Thapa $\mathbf{J}^{1}$, Sah $\mathbf{R}^{1}$}

${ }^{1}$ Paropakar Maternity and Women's Hospital, Thapathali, Kathmandu

Received: 19-May-2017; Accepted: 30-May-2017

Aims: The objective of the study was to evaluate the relationship between admission cardiotocography and fetal outcome among high risk obstetrics patients.

Methods: The study was a hospital based observational study of 130 patients, conducted at Paropakar maternity and Women's Hospital, Kathmandu from January 2014 to June 2014. A 20-minute cardiotocography reading was done in admission room and reading was categorized in 3 groups- reactive, equivocal and ominous. The results were compared to see the relationship between normal and abnormal admission test in terms of color of liquor, mode of delivery, Apgar score at 5 minutes, neonatal resuscitation needed and NICU admission.

Results: Result of admission test (AT) was reactive in 95(73.1\%), equivocal in 19(14.6\%) and ominous in 16(12.3\%) which has significant relationship with mode of delivery ( $p$-value $=0.003$ ), color of liquor ( $p$-value $=0.000$ ), Apgar score at 5 minutes ( $p$-value $=0.000)$ and perinatal outcome ( $p$-value $=0.00)$. Incidences of vaginal deliveries were more common when the test was reactive whereas operative deliveries were more common when the AT was ominous/equivocal.

Conclusions: Admission test is simple, cost effective and non-invasive technique for detecting fetal hypoxia and predicting fetal outcome that can serve as a screening tool in triaging fetuses of high-risk patients in developing countries with a heavy workload and limited resources.

Keywords: admission test, Apgar score, cardiotocography, labour, mode of delivery, neonatal resuscitation

DOI: http://dx.doi.org/10.3126/njog.v12i1.18982

\section{INTRODUCTION}

Pregnancy and labor are normal physiological processes but may be complicated by conditions that need additional ways of assessment of fetal wellbeing. These conditions include medical illnesses such as essential hypertension, pre-eclampsia, renal and autoimmune disease, maternal diabetes and thyroid disease ${ }^{1-4}$,other conditions such as prolonged pregnancy, vaginal bleeding, reduced fetal movements and prolonged ruptured membranes 5 and fetal conditions such as intrauterine growth restriction, fetal infection and multiple pregnancies which increase the risks to the fetuses. ${ }^{5,6}$ Hence, surveillance of the fetus during labor is important to ensure the delivery of a healthy baby with minimum of intervention. ${ }^{7}$ Until the second half of $20^{\text {th }}$ century, assessment of the fetal condition depended on very limited means such as the fetal movement perceived by the mother, growth of the uterus and its contents and the intermittent auscultation by stethoscope. ${ }^{8}$

\section{CORRESPONDENCE}

Dr Jwala Thapa

Paropakar Maternity and Women's Hospital,

Thapathali, Kathmandu

Phone: +977-9851157441,

Email: thapa.jwala2@gmail.com
Cardiotocography is the most widely used indirect diagnostic technique to monitor fetus during pregnancy and labor. ${ }^{9}$ It has been proven to be useful $^{9}$ especially in antepartum period; leading to considerable reduction of perinatal morbidity and mortality. It is performed after admission of the mother to labor ward. ${ }^{10}$ It was introduced as a screening test to detect compromised fetuses on admission and to select women in need of continuous electronic fetal monitoring during labor ${ }^{11}$ where there is lack of resources for its use in every patient.

Developing countries account for most of the global burden of perinatal deaths. ${ }^{12,13}$ So, it is important to utilize the available resources for early diagnosis of high risk patients for successful perinatal outcome.

The purpose of the study was to evaluate the relationship between admission cardiotocography and fetal outcome among high risk obstetrics patients in terms of normal and abnormal admission test and Apgar score at 5 minutes, color of liquor and mode of delivery.

\section{METHODS}

The study was a hospital based observational study conducted at Paropakar Maternity and Women's Hospital (PMWH) from January 2014 to June 2014 for a duration of 6 months. Ethical approval was 
obtained from the hospital and verbal informed consent was taken from the patients. A total of 130 high risk obstetrics cases were included in the study. The inclusion criteria were women with period of gestation $\geq 37$ weeks of gestation with high risks such as bad obstetric history, previous history of stillbirth, pregnancy with concurrent medical illness like hypertension, diabetes mellitus, renal disease, pregnancy induced hypertension/pre-eclampsia, premature rupture of membrane (PROM), intrauterine growth restriction (IUGR), oligohydramnios/ polyhydramnios, Rhesus negative status, postdated pregnancy and diminished fetal movements. The exclusion criteria were ultrasonography confirmed lethal congenital anomaly of the fetus, acute hypoxic states like abruption of placenta, cord prolapse, uterine scar rupture, multiple pregnancies, abnormal lie and presentation, women admitted for induction and elective Caesarean Section, and women who refused to get enrolled in the study. All women were subjected to an admission CTG, which included a 20 minute recording of FHR and uterine contractions. The results of the admission test were categorized into normal/reassuring, equivocal/suspicious and abnormal/ominous as per the Royal College of Obstetricians and Gynecologists (RCOG) guidelines for the interpretation of CTG tracings. Fetal outcome were noted in terms of Apgar score at five minute and color of the liquor. Record of resuscitation required after delivery, admission to NICU and incidence of intrapartum still birth/neonatal mortality were kept. Data were entered in Microsoft Office Excel Worksheet and statistical analysis was done using SPSS version 20.0 by using chi square test, $p$-value of $<0.05$ was considered as significant.

\section{RESULTS}

Out of the 130 high risk obstetric cases included in the study, result of admission test was reactive in 95 $(73.1 \%)$, equivocal in $19(14.6 \%)$ and ominous in 16 $(12.3 \%)$ [Figure 1].

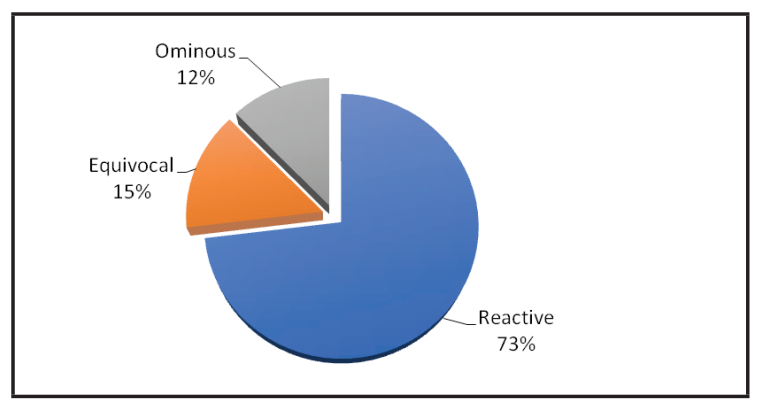

Figure 1: Admission Test Result
Incidences of vaginal deliveries were more common when the test was reactive where as operative deliveries were more common when the AT was ominous/equivocal with significant $\mathrm{p}$-value of $<0.003$ [Table 1].

Table 1: Admission test result and Mode of delivery in study group

\begin{tabular}{|lrrrrrrr|}
\hline Mode of delivery & \multicolumn{9}{c|}{ Result } \\
& \multicolumn{2}{c|}{ Reactive } & \multicolumn{2}{c|}{ Equivocal } & \multicolumn{2}{c|}{ Ominous } \\
& $\mathbf{N}$ & \% & N & \% & N & \% \\
\hline Normal Delivery & 59 & 62.1 & 9 & 47.4 & 2 & 12.5 \\
Caesarean & 26 & 27.4 & 7 & 36.8 & 12 & 75 \\
Instrumental & 10 & 10.5 & 3 & 15.8 & 2 & 12.5 \\
Delivery & & & & & & \\
Total & 95 & 100 & 19 & 100 & 16 & 100 \\
\hline
\end{tabular}

p-value $<0.003$

Incidences of moderate and thick meconium liquor were increased when AT was equivocal and ominous with p-value of 0.000 [Table 2].

Table 2: Admission Test Result and Amniotic Fluid Color

\begin{tabular}{|lllllll|}
\hline Color of A F & \multicolumn{2}{c}{ Reactive } & \multicolumn{2}{c|}{ Equivocal } & \multicolumn{2}{c|}{ Ominous } \\
& N & \% & N & \% & N & \% \\
\hline Clear & 86 & 90.5 & 10 & 52.6 & 3 & 18.8 \\
Moderate & 6 & 6.3 & 7 & 36.8 & 8 & 50 \\
Thick & 3 & 3.2 & 2 & 10.5 & 5 & 31.3 \\
Total & 95 & 100 & 19 & 100 & 16 & 100 \\
\hline
\end{tabular}

p-value 0.000

In reactive AT group, 5.3\% babies had Apgar score less than 7 at five minutes after birth, in equivocal AT group, 36.8\% had Apgar score less than 7 and in ominous AT group, 81.3\% babies had Apgar score less than 7 . It shows that there is a significant relationship between Apgar score and AT results with p-value 0.000 [Table 3].

Table 3: Admission test result and Apgar Score at 5 minute interval

\begin{tabular}{|lllllll|}
\hline Apgar at 5 min & \multicolumn{2}{c|}{ Reactive } & \multicolumn{2}{c|}{ Equivocal } & \multicolumn{2}{c|}{ Ominous } \\
& $\mathbf{N}$ & \% & N & \% & N & \% \\
\hline$<7$ & 5 & 5.3 & 7 & 36.8 & 13 & 81.3 \\
$\geq 7$ & 90 & 94.7 & 12 & 63.2 & 3 & 18.8 \\
Total & 95 & 100 & 19 & 100 & 16 & 100 \\
\hline
\end{tabular}

p-value 0.000

In the reactive AT group only $4.2 \%$ needed resuscitation at birth whereas in the equivocal AT group $31.6 \%$ and in the ominous AT group, 75\% needed resuscitation at birth yielding a p-value of 0.00 showing that there is a significant relationship between patterns of CTG and neonatal resuscitation needed [Table 4]. 
Table 4: Admission Test Result and Neonatal

Resuscitation required

\begin{tabular}{|lllllll|}
\hline $\begin{array}{l}\text { Resuscitation } \\
\text { Required }\end{array}$ & \multicolumn{2}{c}{ Reactive } & \multicolumn{2}{c|}{ Equivocal } & \multicolumn{2}{c|}{ Ominous } \\
& N & \% & N & \% & N & \% \\
\hline No & 91 & 95.8 & 13 & 68.4 & 4 & 25 \\
Yes & 4 & 4.2 & 6 & 31.6 & 12 & 75 \\
Total & 95 & 100 & 19 & 100 & 16 & 100 \\
\hline
\end{tabular}

p-value 0.000

In the ominous AT group, 56.3\% required NICU admission, in the equivocal AT group, $15.8 \%$ required NICU admission whereas in the reactive AT group, only $2.1 \%$ required NICU admission with $p$ value of 0.000 which is statistically significant [Table 5].

Table 5: Admission Test Result and Admission to NICU

\begin{tabular}{|lllllll|}
\hline & \multicolumn{2}{l}{ Reactive } & \multicolumn{2}{c|}{ Equivocal } & \multicolumn{2}{c|}{ Ominous } \\
Admit to NICU & $\mathbf{N}$ & $\mathbf{\%}$ & $\mathbf{N}$ & $\mathbf{\%}$ & $\mathbf{N}$ & $\mathbf{\%}$ \\
\hline No & 93 & 97.9 & 16 & 84.2 & 7 & 43.8 \\
Yes & 2 & 2.1 & 3 & 15.8 & 9 & 56.3 \\
Total & 95 & 100 & 19 & 100 & 16 & 100 \\
\hline
\end{tabular}

p-value 0.000

\section{DISCUSSION}

Screening for fetal distress is a big challenge for obstetricians. Different studies have offered different and at times diametrically opposite recommendations. The concept of cardiotocography was floated to differentiate between mothers who may require continuous fetal monitoring and those who can be managed by intermittent auscultation. The present study was conducted to determine the effectiveness of labor admission test to detect if fetal hypoxia was already present or had the potential to develop during labor.

In the present study population out of $130 \mathrm{AT}$ results, $95(73.1 \%)$ was reactive, $19(14.6 \%)$ was equivocal and $16(12.3 \%)$ was ominous. Similar results were seen in study done by Rahman et $\mathrm{al}^{14}$ where out of $160 \mathrm{AT}$ results, $77 \%$ was reactive, $14.4 \%$ was equivocal and $8.7 \%$ was ominous.In study done by sandhu et $\mathrm{al}^{15}$ out of 150 consecutive high risk obstetric patients subjected to admission test, $67 \%$ was reactive, $23 \%$ was equivocal and $10 \%$ was ominous. Rahman et al $^{16}$ conducted admission test in 176 pregnant women (both high risk and low risk). The results of the AT were reactive in $82.38 \%$, equivocal in $10.22 \%$ and ominous in $7.38 \%$ women. Ingemarsson et $\mathrm{al}^{17}$ conducted admission test in 1043 low risk pregnancy. They observed reactive pattern in $982(94.3 \%)$ patients, equivocal in $49(4.7 \%)$ and ominous in $10(1 \%)$ patients. The study included only low risk obstetric cases that may be the reason for the difference in admission test results. Habibullah et $\mathrm{al}^{18}$ performed AT on 100 high risk pregnancies and found that $79.1 \%$ of patients had reactive AT, $13.5 \%$ had equivocal and $7.1 \%$ had ominous AT results. This study is similar to present study as regard to sample size and inclusion of high risk cases and the results are also comparable. Shantha et al ${ }^{19}$ conducted AT in 100 high risk obstetric cases. The admission test results were reactive in $89.9 \%$, equivocal in $5.31 \%$ and ominous in $4.8 \%$. The results are different from present study though similar in terms of sample size and inclusion of high risk cases.

In study of Rahman et $\mathrm{l}^{14} 9 \%$ of patients with reactive AT group had moderate to thick meconium stained liquor, 39\% with equivocal AT group had moderate to thick meconium stained liquor where as $72 \%$ patients with an ominous test had moderate to thick meconium stained liquor which was statistically significant. Likewise, in the present study also $6.3 \%$ and 3.2\% of the patients with reactive AT group had moderate and thick meconium stained liquor respectively. In equivocal AT group, $36.8 \%$ and $10.5 \%$ of the patients had moderate and thick meconium stained liquor respectively. In ominous AT group, 50\% and 31.3\% of the patients had moderate and thick meconium stained liquor. In a cross-sectional study conducted by Rahman et $\mathrm{al}^{16}$ among 176 pregnant women (both high and low risk), the incidence of moderate to thick meconium stained liquor were more in ominous group $(61.5 \%)$ and equivocal group (33.3\%) in compared to reactive group (4.8\%). It was statistically significant with p-value $<0.001$. In a study of Farkhunda et $\mathrm{al}^{20}$ meconium stained amniotic fluid was more common in non reactive CTG $(22.2 \%)$ than in reactive group $(15.9 \%)$. So they concluded the possibility of fetal compromise in all cases with meconium stained liquor and non reactive CTG.

Incidences of vaginal delivery were more common when the test was reactive compared to operative delivery. On the other hand operative deliveries were more common when the AT was ominous / equivocal compared to the reactive group. Among the reactive AT group of 95 cases, 9 patients (9.5\%) had moderate to thick meconium stained liquor but 36 patients $(37.9 \%)$ underwent intervention in form of operative as well as instrumental deliveries. The high percentage of intervention in reactive AT group may be because of the study group which 
comprised of only high risk cases. The most common indication for operative/instrumental delivery was non-progress of labor $(80 \%)$. Among the equivocal AT group of 19 cases, 9 patients (47.4\%) had moderate to thick meconium stained liquor and 10 patients $(52.6 \%)$ underwent intervention in form of operative and instrumental deliveries. Among the ominous AT group of 16 cases, 13 patients $(81.3 \%)$ had moderate to thick meconium stained liquor and 14 patients (87.5\%) underwent intervention in form of operative and instrumental deliveries. The most common indication in non -reactive group was for fetal distress (75\%). The present study has similar findings with Rahman et $\mathrm{al}^{14}$ where in reactive AT group of 123 cases, 65 (52.8\%) had normal vaginal delivery, 44 (35.8\%) had LSCS and 14(11.4\%) had instrumental delivery. In equivocal AT group of 23 cases, $12(52.2 \%)$ had normal vaginal delivery, 10 (43.5\%) had LSCS and 1 (4.3\%) had instrumental delivery. In ominous AT group of 14 cases, 2(14.3\%) had normal vaginal delivery, 11(78.6\%) had LSCS and $1(7.1 \%)$ had instrumental delivery. The study by Rahman ${ }^{16}$ showed that operative delivery for fetal distress was required in only $5.5 \%$ women of the reactive group, in $27.8 \%$ of equivocal group and in $84.6 \%$ of the ominous group. The low percentage of operative deliveries in reactive and equivocal groups may be because the cases with equivocal trace were placed on continuous CTG monitoring. Continuous electronic fetal monitoring was not available in low resource setting like ours with heavy workload. In study conducted by Kulkarni et a ${ }^{21}$ rate of operative delivery in reactive group was $5.17 \%$ and in ominous group it was $28.5 \%$. This also shows that the rate of operative delivery in omninous group was higher than in reactive and in equivocal group.

Fetal distress was considered to be present when Apgar score at 5 minutes after birth was $<7$ in the present study. Out of 130 deliveries, total 25 (19.2\%) of babies had Apgar score $<7$ at 5 minutes after birth and the rest 105 babies (80.8\%) had Apgar score $\geq 7$. In Reactive AT group, out of 95 (73.1\%) cases, $9(9.5 \%)$ had moderate to thick meconium stained liquor, $36(37.9 \%)$ underwent intervention and 5 (5.3\%) had Apgar score $<7$. Most of the cases who had Apgar score $<7$ had moderate to thick meconium. In equivocal AT group, out of 19 (14.6\%) cases, 9 $(47.4 \%)$ had moderate to thick meconium stained liquor, $10(52.6 \%)$ underwent intervention and 7
(36.7\%) had Apgar score < 7 . In ominous AT group, out of $16(12.3 \%)$ cases, $13(81.2 \%)$ had moderatethick meconium stained liquor, $14(87.5 \%)$ underwent intervention and 13(81.2\%) had Apgar score $<7$. This high percentage in ominous AT group shows the significant relationship between the abnormal CTG pattern and fetal distress as evident by babies with Apgar score $<7$ at five minutes after birth. In a study by Rahman et $\mathrm{al}^{14} 8.9 \%$ of the cases from reactive AT group of $77 \%$ had moderate to thick MSL where $6.5 \%$ had babies with Apgar score $<7$. Likewise in $14.4 \%$ of equivocal AT group, $39.1 \%$ had moderate to thick MSL where $26.1 \%$ had babies born with Apgar score $<7$. In $8.7 \%$ of women with ominous AT group, $71.4 \%$ had moderate to thick MSL where 64.3\% had babies born with Apgar score <7.In this study the evidence of fetal distress was further strengthened by cord blood $\mathrm{PH}$ but still the results are very much comparable to the present study. In a study done by Sandhu et $\mathrm{a}^{22}$ in reactive AT group of 101(67.3\%) cases, $4 \%$ of babies had Apgar score $<7$ at five minutes after birth. In equivocal AT group of $34(22.7 \%)$ cases, $26.5 \%$ had Apgar score $<7$ and in ominous AT group of $15(10 \%)$ cases, $53.3 \%$ had Apgar score $<7$. The study is comparable with the present study. The finding of present study is also comparable to study conducted by N Shantha et a ${ }^{19}$ where Apgar score $<7$ at five minutes was 1 out of 88 in reactive group and 5 out of 9 in ominous group.

Assessment of the fetal outcome was done in terms of neonatal resuscitation needed at the time of birth and NICU admission in relation to admission test. In the present study out of 130 babies, 22 babies $(16.9 \%)$ required resuscitation and 14 babies $(10.8 \%)$ required NICU admission. Out of 22 (16.9\%) babies who required resuscitation, $14(63.6 \%)$ were admitted in NICU. After admission in NICU, five babies were discharged after observation for 24 hours and six babies were discharged after being treated with antibiotics for 10 days. The remaining three babies who were all from ominous AT group were referred to higher specialty center and were followed and known that there were no mortalities. Thus the above finding suggests that babies from reassuring CTG required less resuscitation and NICU admission. The findings were similar with the study done by Rahman et $\mathrm{al}^{16}$ where incidences of NICU admission was significantly high in babies delivered from mother with ominous test group (62\%) compared to those 
with equivocal test group (28\%) and reactive test group $(3.45 \%)$. In study by Sandhu et $\mathrm{al}^{22}$ neonatal admission to NICU was required in $1 \%$ of cases with a reactive AT, $12 \%$ of cases with an equivocal AT and $33 \%$ of cases with an ominous AT $(p<0.01)$. In a study in Lahore, Noreen et $\mathrm{al}^{23}$ also found that majority of women with decelerations had most of the abnormal outcomes where $10 \%$ of babies were admitted to NICU.

\section{CONCLUSIONS}

The admission cardiotocography is a simple, cost effective and non-invasive test in admission room that can serve as a screening tool in triaging fetuses of high-risk obstetric patients. There is significant relationship between AT results and mode of delivery and between AT results and fetal distress. The study showed that the babies from reactive CTG required less resuscitation and NICU admission whereas the babies from abnormal CTG required more resuscitation and NICU admission.

\section{REFERENCES}

1. Lloyd C. Hypertensive disorders of pregnancy. In: Fraser DM, Cooper MA editor(s). Myles textbook for midwives. 14th Edition.Edinburgh: Churchill Livingstone. 2003:357-71.

2. Lloyd C. Common medical disorders associated with pregnancy. In: Fraser DM, Cooper MA editor(s). Myles textbook for midwives.14th Edition. Edinburgh: Churchill Livingstone. 2003:321-55.

3. Nelson CP, Williamson C. Medical disorders in pregnancy. In: Chamberlain G, Steer P editor(s). Turnbull's obstetrics. $3^{\text {rd }}$ Edition. Edinburgh: Churchill Livingstone. 2001:275-97.

4. National Institute for Health and Clinical Excellence. Diabetes in pregnancy: CG63. London: RCOG Press, 2008.

5. Gribbin C, Thornton J. Critical evaluation of fetal assessmen methods. In: James DK, Steer PJ, Weiner CP editor(s). High risk pregnancy management options. Elsevier. 2006.

6. Fisk NM, Smith RP. Fetal growth restriction; small for gestational age. In: Chamberlain G, Steer P editor(s) Turnbull's Obstetrics. $3^{\text {rd }}$ Edition. Edinburgh: Churchill Livingstone. 2001:197-209.

7. Whittle MJ, Martin WL. Fetal monitoring in labor. In: Chamberlain G, steer P, editors.Turnbull'sobstetrics. London:Churchill Livingstone. 2001.

8. De Snook. Text book of Obstetrics.Groningen:Wolters;1946.

9. Van HP. Developments in CTG analysis. Bailleres Clin Obstet Gynaecol. 1996;10:185-207.

10. Ingemarsson I, Arulkumaran S, Ingemarsson E, Tambyraja RL, Ratnam SS. Admission test: A screening test for fetal distress in labor. Obstet Gynecol. 1986;68:800-6.

11. Bix E, Reiner LM, Klovning A, Oian P. Prognostic value of the labor admission test and its effectiveness compared with auscultation only: a systematic review. Br J Obstet Gynaecol. 2005;112:1595-604.

12. Abuhabib N, Lie RT, Oneko O, Shao J, Bergs P, Daltveit AK. Sociodemographic characteristics and perinatal mortality among singletons in North East Tanzania: a registry-based study. J Epidemiol Community Health. 2008;62:960-5.

13. Zupan J. Perinatal mortality in developing countries. N Engl J Med. 2005;352:2047-8

14. Rahman H, Renjhen P, Dutta S, Kar S. Admission cardiotocography: its role in predicting foetal outcome in highrisk obstetric patients. Australasian Med J. 2012;5(10):522-7.

15. Sultana J, Chowdhury TA, Begum K, Khan MH. Comparison of normal and abnormal cardiotocography with pregnancy outcomes and early neonatal outcomes. Mymensingh Med J. 2009;18( Suppl 1):S103-7.

16. Rahman H, Renjhen P, Dutta S. Reliability of admission cardiotocography for intrapartum monitoring in low resource setting. Niger Med J. 2012;53:145-9.

17. Ingemarsson I, Arul Kumaran S. Admission test: a screening test for fetal distress in labor. Obstet Gynecol. 1998;68(6):800-

18. Habeebullah S, Halder MS, Rajaram P. Non stress test in high risk pregnancy. J Obstet Gynecol India.1991;303-7.

19. Shantha N, Shyamla N, Shameem S. Evaluation for role of non stress test in high risk pregnancy. J Obstet Gynecol India. 1999:33-5.

20. Khursheed F, Das CM, Jatoi N. Cardiotocography: obstetric and neonatal outcome. Journal of Rawalpindi Medical College. 2009;13(2):86-8.

21. Kulkarni AA, Shrotri AN. Admission test: A predictive test for fetal distress in high risk labor. Journal of Obstet Gynecol Res. 1998;24(4):255-9.

22. Sandhu VSM, Raju R, Bhattacharyya TK, Shaktivardhan Admission cardiotocography screening of high risk obstetric patients. MJAFI. 2008;64:43-5.

23. Noreen R, Saleem ST, Zaman MF, Saleem T. Fetal out come in caesarean section after abnormal cardiotocography. Med Forum. 2010; 21( 8) 